One in four patients claimed they did not consider themselves ill in any way. Johnson ${ }^{5}$ has reported a similar finding in a comparable population. The patient's concept of his "sick role" is particularly relevant in this context.

\section{“TOLD NOTHING"}

Virtually all patients had seen their family doctor shortly before the interview and knew that specialist referral had been arranged. Yet a third claimed they had been told nothing about why this had been done nor what was involved. Ley and Spelman $^{6}$ have shown that patients remember relatively little of their interview with a doctor, and it is possible that the above reports merely reflect a failure of retention of information. However, in view of their otherwise detailed acccounts of the consultations at which referral had been arranged this explanation does not seem likely. It is much more probable that general practitioners do not sufficiently prepare their patients for the psychiatric consultation they are arranging. Balint ${ }^{7}$ and Shepherd et al. ${ }^{8}$ have commented on the difficulties experienced by a practitioner in expressing to his patient the need for a psychiatric opinion. Kessel ${ }^{9}$ suggests that few family doctors know what psychiatrists do, and their individual attitudes towards the psychiatric services vary widely. ${ }^{10}$

For the practitioner to disguise the nature of the referral may allow his interview to run more smoothly or comfortably at the time, but it can gain nothing in the long run, It is not necessary for the referring doctor to have an extensive knowledge of psychiatry in order to enlighten his patient. The great majority of people interviewed $(80 \%)$ used the opportunity of the research visit to discuss their concerns and misapprehensions about seeing a psychiatrist. They would have welcomed and should have had, the chance to have talked about these feelings to their family doctor. The mystery surrounding the psychiatric clinic should be dispelled. Implementation of these simple measures might go a long way to improving the present poor attendance rate for new patients.

I thank those consultants of the departments of psychiatry at the University Hospital of South Manchester and Manchester Royal Infirmary who allowed me to interview their patients. I also thank Professor Neil Kessel and Professor David Goldberg for their help and advice in the preparation of this paper.

The study was supported by the department of psychiatry, Manchester University, and was conducted during the course of an elective period as a medical student.

\section{References \\ 1 Burgess, J., and Harrington, J., Case Conference, 1964, 11, 59. Grold, L. J., and Hill, W. G., American fournal of Psychiatry, 1962, 119, \\ 3 Humphrey, M., British fournal of Medical Psychology, 1968, 41, 249. \\ Gillis, L. S., and Egert, S., The Psychiatric Outpatient-Clinical and Organisational Aspects, p. 92. London, Faber and Faber, 1973. \\ 5 Johnson, D. A. W., British fournal of Psychiatry, 1973, 123, 185 \\ 6 Ley, P., and Spelman, M. S., Communicating with the Patient. London, Staples Press, 1967. \\ 7 Balint, M., The Doctor, his Patient and the Illness, p. 95. London, Pitman, 1968. \\ ${ }^{8}$ Shepherd, M., et al., Psychiatric Illness in General Practice, p. 160. Oxford University Press, 1966 \\ 9 Kessel, N., Lancet, 1963, 1, 1092 \\ 10 Rawnsley,, K., and Loudon, J. B., British fournal of Preventive and Social Medicine, 1962, 16, 174.}

\title{
Tolerance of Debility in Elderly Dependants by Supporters at Home: Its Significance for Hospital Practice
}

\author{
J. R. A. SANFORD
}

British Medical fournal, 1975, 3, 471-473

this type of admission and may have far-reaching social and economic implications.

\section{Summary}

Some $12 \%$ of all geriatric admissions to University College Hospital and Whittington Hospital are for patients whose relatives or friends can no longer cope with them at home. The person principally involved with home support was interviewed in 50 such cases. The causes of inability to cope were identified on a quantitative and qualitative basis. The supporters were asked to assess which of the problems identified would have to be alleviated to restore a tolerable situation at home; 46 $(92 \%)$ were able to do so. Identification of the "alleviation factors" forms a therapeutic and prognostic guideline in

\footnotetext{
University College Hospital, London, and Whittington Hospital, London

J. R. A. SANFORD, M.B., M.R.C.P., Senior Registrar
}

\section{Introduction}

To some extent social considerations affect all patients admitted to a geriatric unit and in many cases they predominate. For example, admissions are sometimes undertaken to enable relatives to take a holiday or because the patient can no longer manage alone. Another consideration, which forms the subject of this study and which gives rise to a large proportion of all geriatric admissions, is that those who live with and support the patient at home may no longer be able to cope.

There is little documented information on the type and frequency of problems encountered by supporters or their attitude to the long-term welfare of their dependant. Which problems do they feel able to cope with ? Which do they regard as an absolute barrier to home management? Until these questions are answered in individual cases it is not possible to organize therapy or make a rational assessment of prognosis. 
Until the pattern as a whole is established, resources and research cannot be directed efficiently.

\section{Present Study}

The study was undertaken in the geriatric units of a teaching hospital and a district general hospital in London between April and November 1974. Fifty cases were investigated. None were included in which admission was for a medical emergency. There were two reasons for studying the supporters rather than the dependants: firstly they have been largely ignored by formal research and, secondly, the supporter is the "hub" around which the future of the patient revolves.

The information was obtained from the person principally supporting the dependant at home. There was rarely any difficulty in deciding which of the family this was. In 36 cases $(72 \%)$ only one person lived with the dependant. In the remaining cases, in which two or more people lived with the dependant, the burden of care was evenly distributed in only one family. Of the principal supporters 22 were spouses (16 F., 6 M., mean age 74 years), 23 were offspring (19 F., $4 \mathrm{M}$., mean age 56 years), two were sisters (mean age 76 years), two were unrelated (women, mean age 67 years), and one was a daughterin-law (age 60 years).

All 50 supporters were interviewed by me. The information was recorded on a standard form rather than a questionnaire, which might have limited the amount of information obtained.

Problems encountered by the supporters, which in some cases were intolerable, fell into three groups: (1) dependants' behaviour patterns; (2) their own limitations related to the dependant; (3) environmental and social conditions.

Once the problems had been elucidated and classified the supporter was asked to state which ones would need to be alleviated to restore a tolerable situation at home. The problems thus identified were termed "alleviation factors." Identification of these made it possible to express the degree of tolerance shown by the supporters to each problem.

\section{Results}

All the supporters interviewed were able to define the problems encountered in managing their dependant at home. Forty-six $(92 \%)$ could envisage a situation in which they could accept the patient home and could identify the problems that would need to be alleviatedthat is, the alleviation factors. Only four of the supporters (8\%) would not consider having the patient at home again under any circumstances.

The frequency with which group 1 problems were identified (patients' behaviour patterns) and the proportion of supporters able to tolerate them (and who did not, therefore, include them as alleviation factors) are shown in table I. Calculation of tolerance makes it possible to gauge the overall degree of severity with which the supporters regarded each problem and adds a qualitative measure of the problems to the quantitative measure of their frequency. Tolerance is derived, using whole numbers, from the following equation:

Problem frequency - alleviation factor frequency

$$
\text { Problem frequency }
$$

For example, 22 supporters identified inability of the dependant to dress unaided as a problem. Five included this as an alleviation factor, and 17 were able to tolerate it; 17 expressed as a percentage of 22 gives a tolerance of $77 \%$ (table I).

Of the group 1 problems sleep disturbance was the most common, being mentioned in $62 \%$ of cases. It was often included as an alleviation factor and was therefore poorly tolerated (tolerance $16 \%$ ). Urinary incontinence $(54 \%$ of cases), however, was rarely included as an alleviation factor and was therefore well tolerated (tolerance $81 \%$ ). Group 1 contained the largest number of different problems in the three groups $(20 ; 57 \%)$ and $75 \%$ of all, problems encountered. It also contained $80 \%$ of the alleviation factors identified.

The group 2 problems (supporters' own limitations related to the dependant) are set out in table II. Nine different ones were identified $(26 \%)$, and $16 \%$ of all the problems encountered were in this group. Group 2 contained $11 \%$ of the alleviation factors.

In group 3 (environmental and social conditions) (table III) six different problems were identified $(17 \%) ; 12 \%$ of all the problems in the study and $9 \%$ of the alleviation factors were in this group.

The total number of different problems in the three groups was 35 and their uverall numerical frequency was 452 . Thus each supporter had a mean of 9 problems. Of the $\mathbf{4 5 2}$ problems, 221 were alleviation factors, giving a mean of $\mathbf{4 . 4}$ for each supporter and showing that
TABLE I-Analysis of Group 1 Problems Identified (Dependants' Behaviour Patterns)

\begin{tabular}{|c|c|c|}
\hline & $\begin{array}{c}\text { Frequency } \\
\text { ( } \% \text { of Cases) }\end{array}$ & $\begin{array}{l}\text { Tolerance (\% of } \\
\text { Supporters Able to } \\
\text { Tolerate Problems) }\end{array}$ \\
\hline 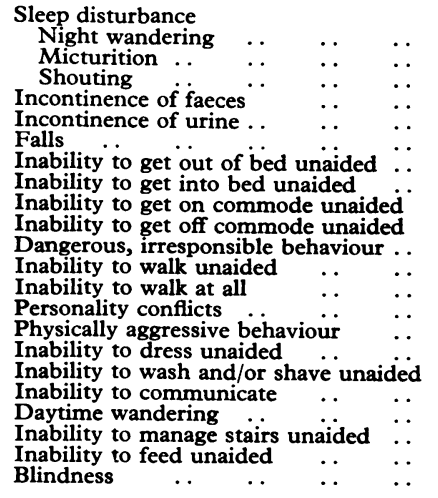 & $\begin{array}{l}24 \\
24 \\
24 \\
10 \\
56 \\
54 \\
58 \\
52 \\
50 \\
36 \\
38 \\
32 \\
18 \\
16 \\
26 \\
18 \\
44 \\
54 \\
16 \\
12 \\
10 \\
12 \\
2\end{array}$ & $\begin{array}{l}24 \\
16 \\
17 \\
20 \\
43 \\
81 \\
52 \\
35 \\
40 \\
22 \\
21 \\
38 \\
33 \\
13 \\
54 \\
44 \\
77 \\
93 \\
50 \\
33 \\
60 \\
67 \\
0\end{array}$ \\
\hline
\end{tabular}

TABLE II-Analysis of Group 2 Problems Identified (Supporters' Own Limitations)

\begin{tabular}{|c|c|c|c|}
\hline & & $\begin{array}{l}\text { Frequency } \\
\text { (\% of Cases) }\end{array}$ & $\begin{array}{l}\text { Tolerance (\% of } \\
\text { Supporters Able to } \\
\text { Tolerate Problem) }\end{array}$ \\
\hline 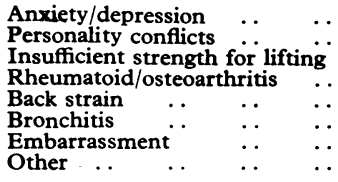 & $\begin{array}{l}\because \\
\because \\
\because \\
\because \\
\because \\
\cdots\end{array}$ & $\begin{array}{r}52 \\
26 \\
22 \\
12 \\
8 \\
6 \\
4 \\
12\end{array}$ & $\begin{array}{r}65 \\
54 \\
73 \\
67 \\
100 \\
33 \\
0 \\
67\end{array}$ \\
\hline
\end{tabular}

TABLE III-Analysis of Group 3 Problems Identified (Environmental and Social Conditions)

\begin{tabular}{|c|c|c|}
\hline & $\begin{array}{l}\text { Frequency } \\
\text { (\% of Cases) }\end{array}$ & $\begin{array}{l}\text { Tolerance (\% of } \\
\text { Supporters Able to } \\
\text { Tolerate Problem) }\end{array}$ \\
\hline $\begin{array}{l}\text { Restriction of social life } \\
\text { Inability to leave dependant for more }\end{array}$ & 42 & 57 \\
\hline 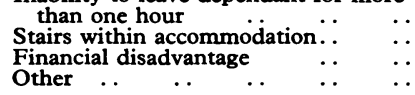 & $\begin{array}{r}28 \\
26 \\
4 \\
4\end{array}$ & $\begin{array}{r}71 \\
85 \\
0 \\
0\end{array}$ \\
\hline
\end{tabular}

TABLE IV-Diagnoses in Dependants which Contributed to their Debility

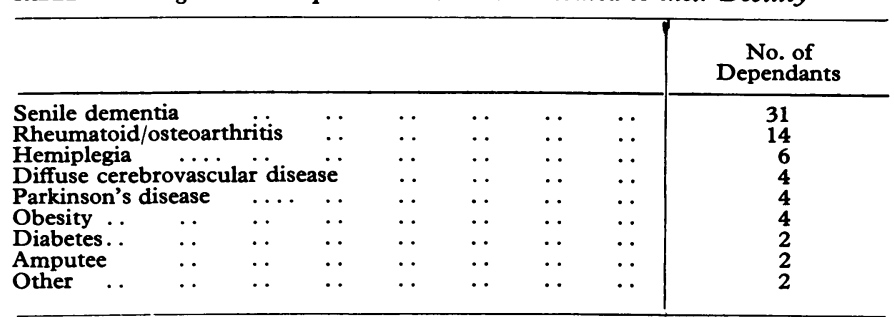

TABLE V-Numbers of Cases in which Social Services were Used and in which there was a Shortfall of Use

\begin{tabular}{|c|c|c|c|}
\hline & & Service Used & Shortfall \\
\hline $\begin{array}{l}\text { District nurse } \\
\text { Meals on Wheels } \\
\text { Incontinence laundry service } \\
\text { Home help }\end{array}$ & $\begin{array}{l}\cdots \\
\cdots \\
\cdots\end{array}$ & $\begin{array}{r}26 \\
8 \\
1 \\
19\end{array}$ & $\begin{array}{r}6 \\
2 \\
15 \\
7\end{array}$ \\
\hline
\end{tabular}

approximately one in every two problems identified was an alleviation factor.

The diagnoses in the dependants thought to have contributed to an intolerable situation for the supporters are given in table IV. Thirty dependants were women aged 70-94 (mean 83 ) years and 20 were men aged 69-92 (mean 79 ) years.

The use made of social services is shown in table V. "Shortfall" refers to cases in which there was a partially or completely unfulfilled need. 


\section{Discussion}

The alternative to home management in almost all of these cases was long-term hospitalization, most patients being too debilitated for part III accommodation. Most supporters were clearly devoted to the dependants and had suffered considerable strain over a prolonged period. ${ }^{1}$ Interestingly $46(92 \%)$ were able clearly to evaluate the problems at home which they could and could not cope with, even during the crisis period surrounding hospitalization of the dependant.

Most of the problems the supporters felt unable to cope with in future home management - the "alleviation factors"-fell into group $1\left(80^{\circ}{ }_{0}\right)$. In this group the most frequent problem was sleep disturbance $(62 \%$ of cases), in which the supporter was woken regularly at night by the dependant for various reasons. This was poorly tolerated $(16 \%)$. This may not be the only type of dependant relationship in which sleep disturbance causes stress; for example, it may be a factor in the battered baby syndrome. Despite the fact that sleep disturbance generated much animosity in the supporters, however, no evidence of "granny battering" was found. The causes of sleep disturbance were night wandering, inability to get on and off the commode unaided (usually for micturition), and irrational shouting. Night wandering is a feature of senile dementia. Clinical experience suggests that a moderate dose of a phenothiazine in the evening may be effective in its control but there are no published data on the subject. The problem of nocturnal micturition may be approached in three ways: either by reducing frequency or by positioning the commode to enable the dependant to reach it unaided or by providing a receptacle for use in bed. The first approach entails treating disorders such as urinary tract infections or congestive heart failure and discouraging fluids in the evening. The second and third approach require common-sense measures but are often neglected.

Another frequent $(56 \%)$ and poorly tolerated (43\%) factor in group 1 was faecal incontinence. As might have been expected, urinary incontinence, while almost as frequent $(54 \%)$, was well tolerated $(81 \%)$. Most cases of faecal incontinence were associated with senile dementia, but inability to get to the commode unaided was, of course, another factor. Treatment is unlikely to prove successful unless a local cause is found-for example, impaction-but efforts should be made to re-establish continence by training and to increase mobility. Because of the difficulty of treatment, faecal incontinence when listed as an alleviation factor implies a bad prognosis for future home management. Fifteen supporters, however, thought that an incontinence laundry service would be of value, and there may be a case for making this service more widely available.

Other frequent and poorly tolerated factors in group 1 were those of general immobility; interestingly, inability to get in and out of bed and on and off the commode were more often encountered and regarded as more of a problem than inability to walk unaided. This indicates a need, both at home and in hospital, to explore the advantages of aids such as low beds and handrails.

Dangerous irresponsibility was mentioned in $32 \%$ of cases though most supporters felt able to contain it by such measures as turning off the gas at source, locking outside doors, and having high-wall electric fires. Advice on these matters can be given to supporters when necessary.

Falls, another problem in group 1, were fairly well tolerated by the supporters if not by the dependants. Worry about the possibility of injury to the dependant was, perhaps surprisingly, overshadowed in most supporters' minds by the difficulty of picking the dependant up, which often required the help of a neighbour or the police.

Frequent though well-tolerated factors in group 1 not often identified as alleviation factors included urinary incontinence, inability to wash unaided, and inability to dress unaided. Most supporters felt able to cope with these problems, often in the case of washing with the aid of a district nurse. Washing the dependant was particularly well tolerated $(93 \%)$, and in this the supporters received the most help from the social services. This does perhaps suggest that outside help for other problems might be of value in enabling supporters to cope.

Factors less often encountered were physically aggressive behaviour by the dependant or specific personality conflicts attributed by the supporter to the dependant's behaviour. A number of different personality conflicts were present including demanding behaviour $(8 \%)$ and a continuing sexual interest $(2 \%)$. Only $16 \%$ of the supporters identified inability to communicate as a problem, and the tolerance of this was $50 \%$.

Group 2 contained only $16 \%$ of all the problems identified and only $11 \%$ of the alleviation factors. The most common problem was anxiety or depression or both (52\% of cases), which was usually attributed to looking after the dependant. Tolerance of this was, perhaps surprisingly, fairly good (65\%). Eleven of the supporters $(22 \%)$ considered that they were just not physically strong enough to cope with lifting, but again this was well tolerated $(73 \%)$. Two supporters, both sons, identified as a problem factor embarrassment in dressing and attending to their mothers on the commode, and both listed this as an alleviation factor, tolerance, therefore, being nil. Interestingly, despite the fact that over half $(59 \%)$ of the supporters in this study were over 65 years old, relatively few problems (16\%) were identified in group 2 . This suggests that we would be mistaken to regard age as synonymous with debility and indicates that it is the old who lead the frail in our society rather than the "frail who lead the frail," as has been suggested. ${ }^{2}$

Group 3 was again much smaller than group 1 and contained only $12 \%$ of all the problems identified and $9 \%$ of the alleviation factors. Restriction of social life was identified in $42 \%$ of cases, and the tolerance of this was $57 \%$. Many supporters had not had a holiday or even an evening out for years and welcomed the idea of a "granny sitter." This was a real unfulfilled need. Fourteen supporters $(28 \%)$ felt unable to leave their dependant for more than an hour, which precluded all activity outisde the home except for a quick visit to the shops. Surprisingly few supporters thought that their environment made matters more difficult. Thirteen $(26 \%)$ identified stairs within their accommodation as a problem, but they usually managed to alleviate this by such measures as bringing the dependant's bed downstairs and obtaining a commode. Tolerance of this problem was therefore high $(85 \%)$. Two supporters $(4 \%)$ considered that they were financially disadvantaged by looking after their dependant, and this was due to having to give up work. A number of supporters were entitled to, but had not been receiving, an attendance allowance.

\section{Conclusion}

The population of England and Wales over 75 years of age is likely to increase by $20 \%$ in the next decade. ${ }^{3}$ There is a deficiency of resources within geriatric units to meet existing needs. This study examines the problems of a group of people who have the potential to reduce the geriatric ward-patient population by as much as $12 \%$. At present their problems are neglected and they are unable to cope with their dependants at home. We would be well advised to consider their needs most carefully for the future.

I should like to thank Professor M. Jefferys and Professor A. N. Exton-Smith for advice and criticism during the preparation of this work.

Requests for reprints should be addressed to me at The General Hospital, Hereford HR1 2PA.

\section{References}

1 Isaacs, B., British Medical fournal, 1971, 4, 282.

2 Cresswell, J., et al., New Society, 1972, 20, 410.

3 Registrar General, Quarterly Return for England and Wales, No. 501. London, H.M.S.O., 1974. 